\title{
O PESSIMISMO REVOLUCIONÁRIO DE WALTER BENJAMIN
}

\author{
MICHAEL LÖWY \\ Centre National de la Recherche Scientifique \\ Paris | França \\ michael.low1@gmail.com \\ orcid.org/0000-0001-56790927
}

O pessimismo cultural que Benjamin reivindica em seu artigo sobre o Surrealismo, de 1929, está resolutamente engajado no campo da esquerda mais radical; aos seus olhos, o pessimismo é um traço comum aos comunistas mais lúcidos - como o trotskista francês Pierre Naville - e aos surrealistas.

Pessimismo - Cultura - Surrealismo - Crítica 


\title{
WALTER BENJAMIN'S REVOLUTIONARY PESSIMISM
}

\author{
MICHAEL LÖWY \\ Centre National de la Recherche Scientifique \\ Paris | France \\ michael.low1@gmail.com \\ orcid.org/0000-0001-56790927
}

The cultural pessimism Benjamin claims in his article on Surrealism, from 1929, is resolutely engaged in the most radical leftish field; from his point of view, pessimism is a trace common to the most lucid communists - like French Trotskyist Pierre Neville - the surrealists.

Pessimism - Culture - Surrealism - Criticism 
O pessimismo cultural (Kulturpessimismus) tem má fama. O termo aparece por volta do início do século XIX para designar uma atitude, um estado de espírito, uma Stimmung ${ }^{1}$ de desconfiança em relação à modernidade, e de crítica contrária ao capitalismo, ao liberalismo e ao industrialismo, partilhada por toda uma corrente da cultura alemã dos anos 1890-1933. Pode-se reduzi-lo a manifestações nacionalistas, racistas e antissemitas preparando o advento do Terceiro Reich? Esta é a tese sustentada, com grande erudição, por Fritz Stern em sua obra "clássica", O pessimismo cultural como perigo político (1961) - é o título da edição alemã - que estuda os escritos de três eminentes representantes da "revolução conservadora": Paul de Lagarde, Julius Langbehn e Moeller van der Bruck. Esses três autores são, sem dúvida, nacionalistas reacionários - e, no que concerne aos dois primeiros, antissemitas notórios - e seus trabalhos sem dúvida, dentre outros, têm alimentado a ideologia nacional-socialista (Stern 1986).

Mas eles são representantes de toda a corrente pessimista cultural? $\mathrm{Na}$ verdade, o Kulturpessimismus, do qual Friedrich Nietzsche é uma das principais referências filosóficas, é um estilo de pensamento muito mais amplo, abrangendo um amplo espectro político e intelectual, e incluindo escritores como Thomas Mann, sociólogos como Ferdinand Tönnies e Max Weber ou filósofos como Oswald Spengler. Seria ainda mais errado identificá-lo com o antissemitismo, uma vez que existe, na cultura germânica da época, um pessimismo cultural judaico, representado, entre outros, por escritores como Stefan Zweig e Joseph Roth.

Se há um pólo conservador ou reacionário, não há menos na Alemanha um pessimismo cultural da esquerda - muitas vezes representado, é verdade, por pensadores judeus. É suficiente mencionar Walter Benjamin ou a Escola de Frankfurt.

O pessimismo cultural que Benjamin reivindica em seu artigo sobre o Surrealismo, de 1929, está resolutamente engajado no campo da esquerda mais radical; aos seus olhos, o pessimismo é um traço comum aos comunistas mais lúcidos - como o trotskista francês Pierre Naville - e aos surrealistas.

Precisamos, ele escreve, de um "pessimismo integral. Sem exceção. Desconfiança acerca do destino da literatura, desconfiança acerca do destino da liberdade, desconfiança acerca do destino da humanidade europeia, e principalmente desconfiança, desconfiança e desconfiança com relação a qualquer forma de entendimento mútuo: entre as classes, entre os povos, entre os indivíduos. E confiança ilimitada apenas no I. G. Farben e no aperfeiçoamento pacífico da Força Aérea”. (Benjamin 1987, 34)

Trata-se aqui de um pessimismo revolucionário que não tem nada a ver com a resignação fatalista, e ainda menos com a variante reacionária e préfascista do pessimismo cultural, porque está a serviço da emancipação das classes oprimidas. Sua preocupação não é o "declínio" das elites, ou da nação, mas as ameaças que o progresso técnico e econômico promovido pelo capitalismo faz pesar sobre a humanidade.

Walter Benjamin representa uma versão revolucionária do pessimismo cultural, que não tem nada a ver com resignação fatalista, e muito menos com uma variante reacionária e pré-fascista do pessimismo cultural, porque está a serviço da emancipação das classes oprimidas. Sua preocupação não é o

\footnotetext{
${ }^{1}$ N.T.: Stimmung é um termo alemão cujo sentido pode ser traduzido por humor ou ambiente ou estar com disposição.
} 
"declínio" das elites, ou da nação, mas as ameaças que o progresso técnico e econômico promovido pelo capitalismo faz pesar sobre a humanidade.

Seu marxismo ganha, assim, uma qualidade crítica que o distingue radicalmente do marxismo "oficial" dominante na época. Essa articulação se manifesta pela primeira vez no livro Rua de Mão Única, escrito entre 1923 e 1926, onde ela encontra-se, sob o título "Alarme de incêndio", essa premonição histórica das ameaças de progresso: se a derrubada da burguesia pelo proletariado "não estiver efetivada até um momento quase calculável do desenvolvimento econômico e técnico (a inflação e a guerra de gases o assinalam, tudo está perdido. Antes que a centelha chegue à dinamite, é preciso que o pavio que queima seja cortado" (Benjamin 1987, 46).

Ao contrário do marxismo evolucionista vulgar, Benjamin não concebe a revolução como resultado "natural" ou "inevitável" do progresso econômico e técnico (ou da "contradição entre forças e relações de produção"), mas como a interrupção de uma evolução histórica conduzindo à catástrofe.

É porque ele percebe esse perigo catastrófico que Benjamin reivindica, em seu artigo sobre surrealismo de 1929, pessimismo - um pessimismo revolucionário que não tem nada a ver com a resignação fatalista, e ainda menos com o Kulturpessimismus alemão, conservador, reacionário e pré-fascista (Carl Schmitt, Oswald Spengler, Moeller van der Bruck): pessimismo está aqui a serviço da emancipação das classes oprimidas. Sua preocupação não é o "declínio" das elites, ou da nação, mas as ameaças que fazem pesar sobre a humanidade o progresso técnico e econômico promovido pelo capitalismo.

Nada parece mais irrisório aos olhos de Benjamin do que o otimismo dos partidos burgueses e da social-democracia, cujo programa político é apenas um "poema de primavera ruim". Contra esse "otimismo sem consciência", esse "otimismo diletante/de amadores", inspirado na ideologia do progresso linear, ele descobre no pessimismo o ponto de convergência efetiva entre surrealismo e comunismo. Não é preciso dizer que não se trata de um sentimento contemplativo, mas um pessimismo ativo, "organizado", prático, inteiramente estendido para o objetivo de impedir, por todos os meios possíveis, o advento do pior.

Pergunta-se a que pode fazer referência o conceito de pessimismo aplicado aos comunistas: sua doutrina em 1928, celebrando os triunfos da construção do socialismo na URSS e a queda iminente do capitalismo, não é ela precisamente um belo exemplo de ilusão otimista? Na verdade, Benjamin tomou emprestado o conceito de "organização do pessimismo" de uma obra que ele qualifica como "excelente", A Revolução e os intelectuais (1926), do comunista dissidente Pierre Naville. Próximo aos surrealistas (ele fora um dos redatores da revista $A$ Revolução Surrealista), Naville tinha naquele momento feito a opção do engajamento político no Partido Comunista Francês, que ele queria compartilhar com esses amigos.

No entanto, para Pierre Naville o pessimismo, que constitui "a fonte do método revolucionário de Marx", é o único meio de "escapar das nulidades e decepções de uma época de compromisso". Recusado o "otimismo bruto" de um Herbert Spencer - a quem ele elogia com o qualificativo amável de "cérebro monstruosamente estreito" - ou de uma Anatole France, cujas "piadas infames" ele não suporta, conclui: "é necessário organizar o pessimismo", "a organização do pessimismo" é a única palavra de ordem que nos impede de definhar" (Neville 1965, 76-77 e 110-117). 
É inútil evidenciar que essa apologia apaixonada do pessimismo era pouco representativa da cultura política do comunismo francês naquela época. $\mathrm{Na}$ verdade, Pierre Naville seria logo expulso do Partido, em 1918. A lógica de seu anti-otimismo o conduziu às fileiras da oposição comunista de esquerda ("Trotskista"), da qual ele se tornou um dos principais dirigentes.

Essa visão crítica permite a Benjamin perceber - intuitivamente, mas com estranha acuidade - as catástrofes que aguardavam a Europa, perfeitamente resumidas pela frase irônica sobre "confiança ilimitada". É claro que mesmo ele, o mais pessimista de todos, não poderia prever as destruições que a Luftwaffe iria infligir às cidades e às populações civis europeias; e ainda menos podia ele imaginar que a I. G. Farben ia, apenas uma dúzia de anos mais tarde, distinguirse pela fabricação de gás Ziklon B usado para "racionalizar" o genocídio, nem que suas fábricas iam empregar, às centenas de milhares, a mão de obra de campos de concentração.

No entanto, único entre todos os pensadores e líderes marxistas daqueles anos, Benjamin teve a premonição dos monstruosos desastres aos quais podia dar à luz o "progresso" no quadro da civilização industrial/burguesa em crise.

\section{REFERÊNCIAS}

BENJAMIN, Walter. O Surrealismo. São Paulo: Brasiliense, 1985.

BENJAMIN, Walter. Rua de mão única. São Paulo: Brasiliense, 1995.

NAVILLE, Pierre. La révolution et les intellectuels. Paris, Gallimard, 1965.

STERN, Fritz. Kulturpessimismus als politische Gefahr, Eine Analyse nationaler Ideologie in Deutschland. Munnich, DTV, 1986.

O pessimismo revolucionário de Walter Benjamin 